\section{Buenos Aires, 1962. El proyecto para la Biblioteca Nacional $\mathrm{La}$ arquitectura y la finalidad}

Buenos Aires, 1962. The Project for the National Library: the architecture and the purpose

Buenos Aires, 1962. O projeto pra a Biblioteca Nacional: a arquitetura e o propósito

DOI: https://doi.org/10.18861/ania.2022.12.1.3194

Arq. Silvio Plotquin

Universidad Argentina de la Empresa splotquin@uade.edu.ar ORCID: https://orcid.org/0000-0002-5912-330X

Recibido: $31 / 10 / 2021$ Aceptado: 03/12/2021

Cómo citar:

EL siguiente trabajo se inscribe dentro del proyecto UADE

INSOD P2OS51_IMAGEN Y EMOCIÓN. PLEXO ENTRE

FILOSOFÍA Y PSICOLOGíA, que dirigió el Dr.Walter Cenci.

UNIVERSIDAD ARGENTINA DE LA EMPRESA. Buenos Aires,

Resumen

El drama que desnudó el final de la Segunda Guerra, forzó la reintroducción del debate por la forma arquitectónica, más allá de una limitada ficción desapasionada y racional de la función. Cuando la función dejó de ser el patrón unitario contra el que comparar a los edificios modernos, críticos e historiadores debieron disponer de nuevos espejos: monumentalidad, el proceso de producción, el usuario, la ciudad, la forma, el genius loci, la Historia, la tradición o la cultura. En el siguiente artículo, se verificarà la formulación de imágenes arquitectónicas como catalizadoras por caso, del concepto de finalidad en arquitectura pública, tal como ha querido ser presentada en torno del concurso de la sede definitiva de la Biblioteca Nacional en Buenos Aires de 1962, en cuya arquitectura, a un rasgo de organización eficiente y provechosa, se superpuso por la forma, un rasgo de carácter manifiesto, redundante y dramático- con el arrojo que presupone.

Palabras clave: forma, función, diseño, desarrollismo, neobrutalismo, sistemas, finalidad, modernidad, monumentalidad, significación.
Abstract

The drama revealed by the end of the Second War, forced the reintroduction of the debate on architectural form, beyond a limited dispassionate and rational fiction of function. When function ceased to be the unitary pattern against which to compare modern buildings, critics and historians had to have new mirrors: monumentality, the production process, the user, the city, the form, the genius loci, the History, tradition or culture. In the following article the formulation of architectural images as catalysts of the concept of purpose in public architecture will be verified, as it was presented around the contest for the ultimate headquarters of the National Library in Buenos Aires in 1962, in whose architecture a feature of a manifest, redundant and dramatic character was superimposed by form to an efficient scheme and profitable organization.

Keywords: form, function, design, developmentalism neobrutalism, systems, purpose, modernity, monumentality, significance.

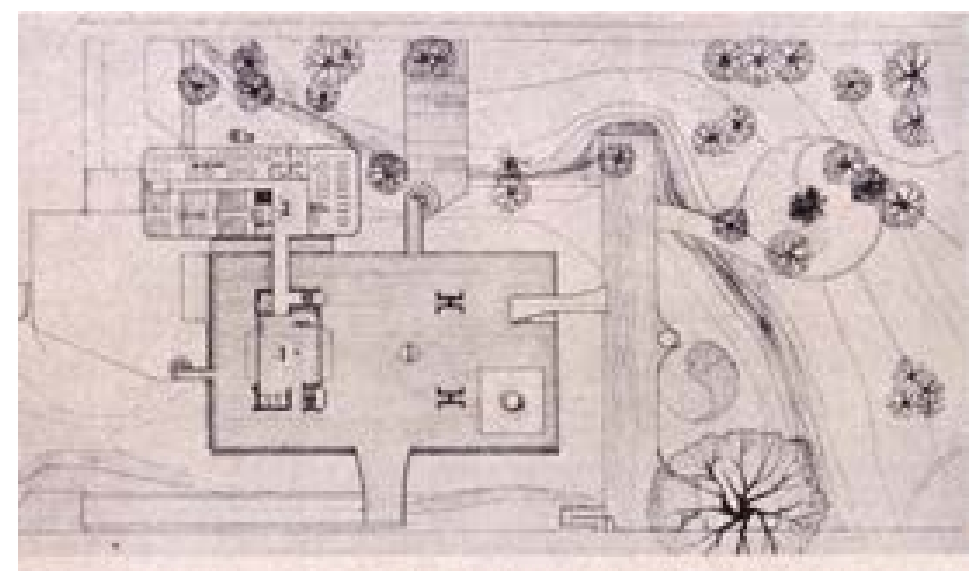

Resumo

O drama revelado no final da Segunda Guerra, forçou a reintrodução do debate sobre a forma arquitetônica, para além de uma ficção de função limitada e imparcial. Quando a função deixou de ser o padrão unitário contra o qual comparar os edifícios modernos, críticos e historiadores tiveram que ter novos espelhos: a

monumentalidade, o processo de produção, o usuário, a cidade, a forma, o genius loci, a História, a tradição ou a cultura. No artigo seguinte será verificada a formulação de imagens arquitetônicas como catalisadores do conceito de finalidade na arquitetura pública, tal como foi apresentado em torno do concurso para a sede definitiva da Biblioteca Nacional de Buenos Aires em 1962, em cuja arquitetura um recurso de caráter manifesto, redundante e dramático foi sobreposto pela forma a um esquema eficiente e uma organização lucrativa.

Palavras-chave: forma, função, design desenvolvimentismo, neobrutalismo, sistemas, propósito modernidade, monumentalidade, significado. 
La cuestión de la imagen no debe ser dada por sentada en arquitectura. Durante gran parte de su historia moderna, de lado no ya la figuración, sino todo tipo de mímesis de lado no ya la figuresentación de cierto ideal estético excepto por la representación constituyó una cualidad sin rango, derivada de lo que el concepto "función" significi la lucha por la supervivencia de la especie, la organicidad de un sistema de vísceras, el movimiento ficaz y letánico de un sistema de vísceras, el movimiento eficaz y letánico de una máquina (Behne, 1923, De Fusco, 1967). Desde tal perspectiva, la emoción provenía de la coincidencia entre aprender, conducirse (Groys, 2014). El drama que el final aprender, conducirse (Groys, 2014). É drama que el fina de la Segunda Guerra desnudo, forzó la reintroducción de debate por la forma arquitectónica, más allá de la limitada la función dejó de ser el patrón unitario contra el que comparar a los edificios modernos, críticos e historiadores comparar a los edificios modernos, críticos e historiadores proceso de producción, el usuario, la ciudad, la forma, el genius loci, la Historia, la tradición o la cultura. La pregunt de este escrito será por la finalidad en arquitectura, aquella vez que la función de la función dejó de ser la forma de la forma.

Esa cuestión se intenta responder aquí, en torno de concurso para el proyecto de la sede definitiva de la Biblioteca Nacional en Buenos Aires de 1962, considerado como el regreso de la discusión sobre el monumento en la Argentina desarrolista. El primer capítulo aqu, referirá a la progresiva transformación del concepto de función en finalidad. Un segundo capítulo, referirá a la imagen como finalidad, es decir, como valoracion no exclusivamente práctica, que vincula el proyecto mediante formas, al encargo y al programa. Finalmente, se verificar la formulación de imágenes arquitectónicas como catalizadoras de emociones propiciadas, que responden a concepto de finalidad, en el caso de arquitectura pública, tal como ha querido ser presentada en torno del concurso mencionado. A la arquitectura de la Biblioteca Nacional, como a la auitectura que se producía en 1950 y 1960 , se la llamó también "sistémica" una metáfora tan orgánica como mecánica y solo después de la clasificación de Reyner Banham. "nuevo-brutalista" (Banham, 1955). A un rasgo de una organización eficiente y provechosa se te superpuso por la forma, un rasgo de carácter manifiesto, superpuso por la formático por el arrojo que presupones, ineludible. (Figura 1)

Este artículo es en una comprobación bibliográfica ex post. Fue pertinente reconstruir la finalidad de la Biblioteca como se desprende, no solo de las bases del Concurso de anteproyectos, sino de la memoria de los autores del proyecto, del dictamen de los jurados y de la presentación al público del proyecto premiado No debe esperarse aquí una descripción arquitectónica o proyectual de edificio de la Biblioteca, sino la enumeración de los rasgos arquitectónicos que orientan en la comprensión del concepto de finalidad en arquitectura pública, manifestada como interpretación de las expectativas de los promotores y dirigentes sobre el edificio, por encima de las consideraciones técnicas y funcionales.

\section{Finalidad o función}

El slogan "la forma debe seguir a la función" (en el que se aprecia el impacto de las teorías biológicas y evolucionistas del naturalista J.B Lammarck, muerto en 1829) se atribuyó al escultor Horatio Greenough, autor en 1840 de una estatua de George Washington al tamano natural, con el torso desnudo (Figura 2). El arquitecto de Chicago, Henry L. Sullivan la haría suya en un artículo de finales del siglo XIX (Sullivan, 1896), en relación a la estetica de los rascacielos de oficinas de alquiler (Figura 3). Tal dogma de la escultura, de la que son propios la belleza, el símbolo,

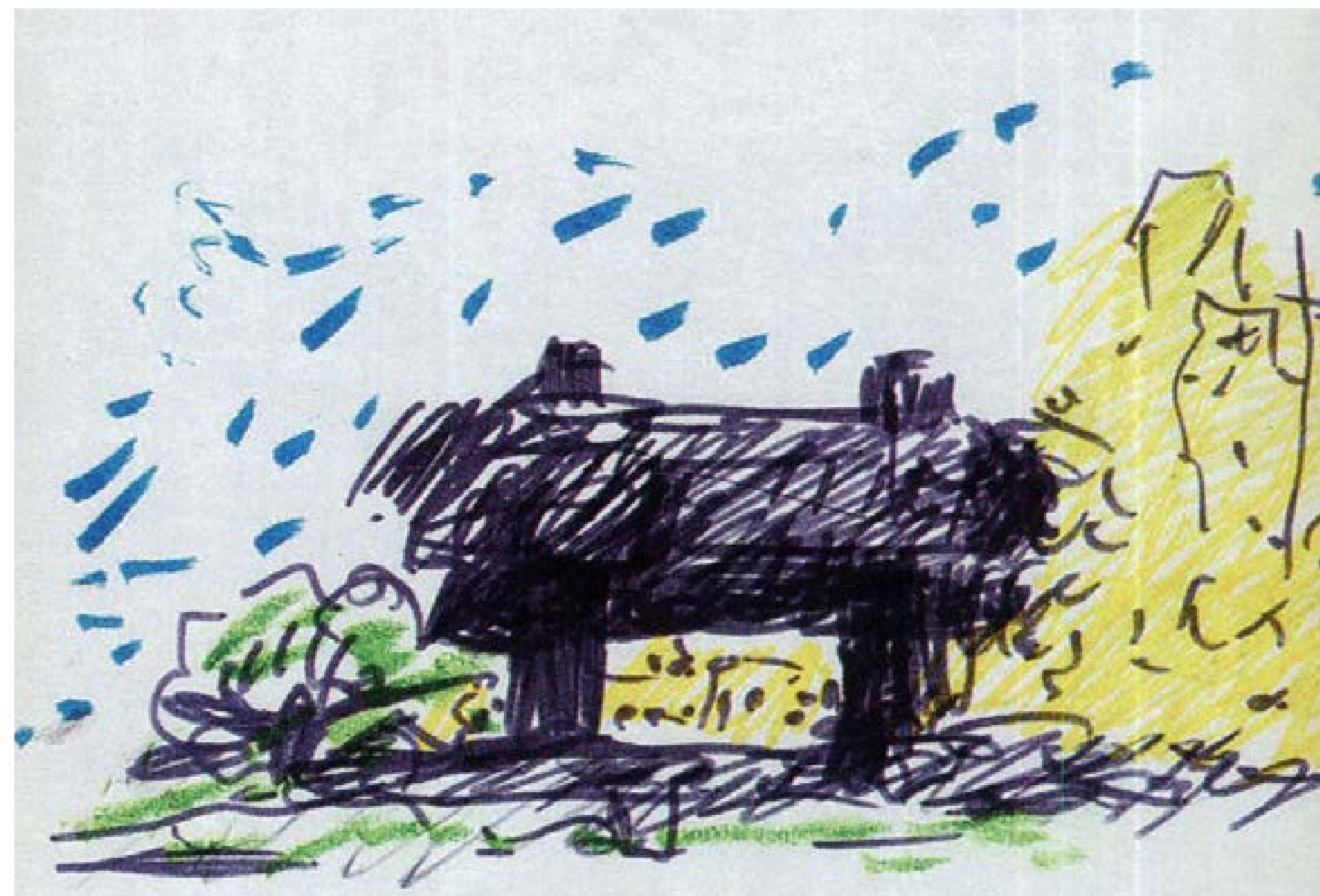

Figura 1. Testa, C. Biblioteca Nacional. Croquis s/ 


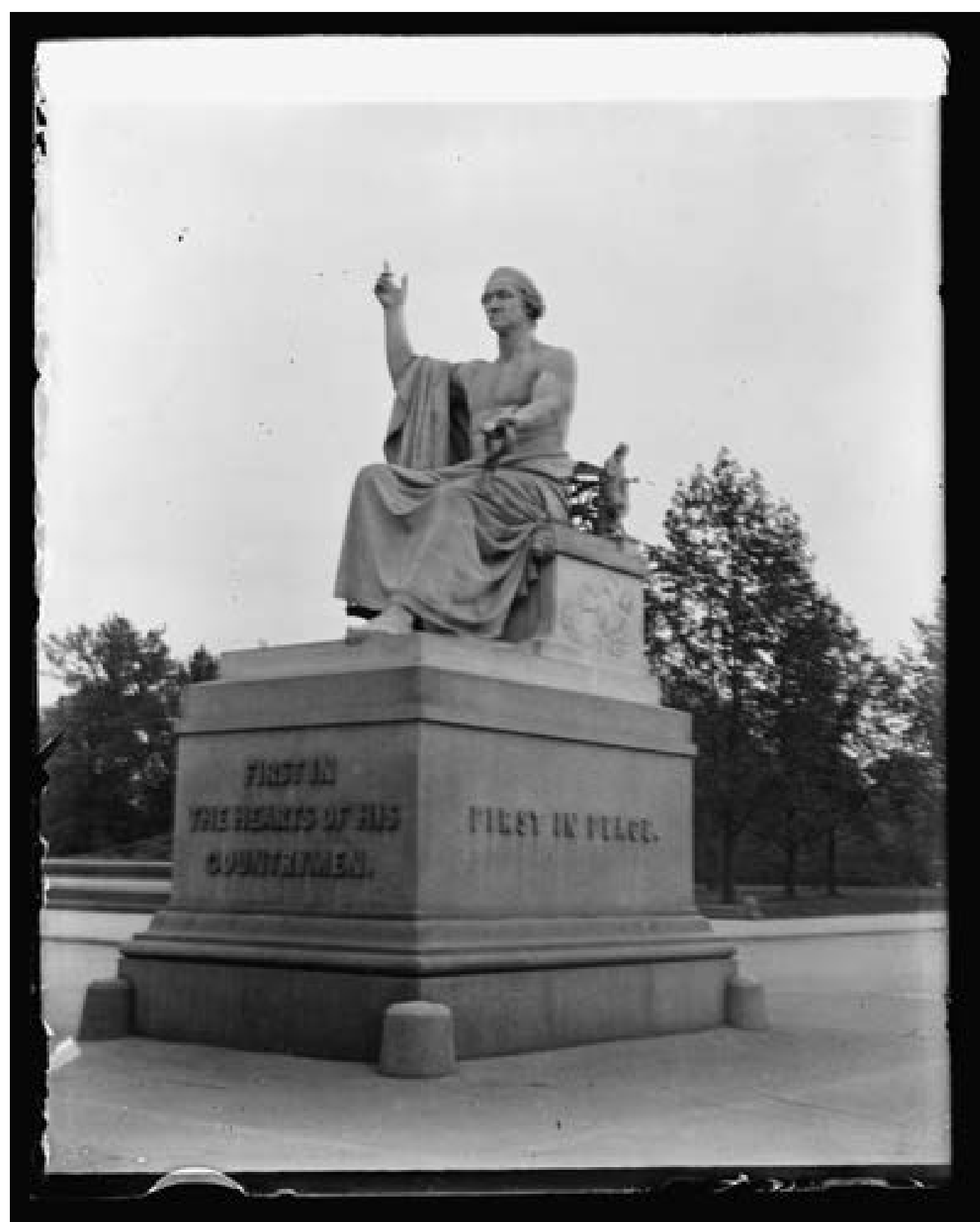

\section{A WHIM AND A CHANCE.}

By WILLIAM T. NICHOLS,

AUTHOR OF "MY STRANOE PATIENT," ETO. ОOMXX.FTE.

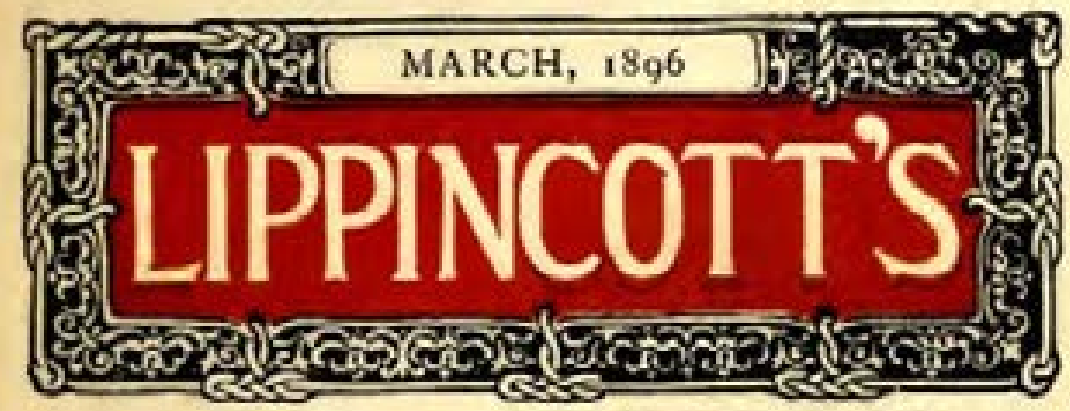

MONTHLY MAGAZINE CONTENTS

A WHIM AND A CHANGE

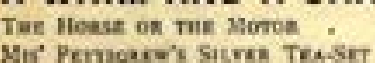

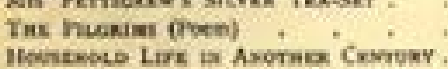

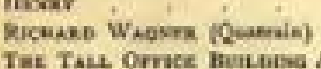

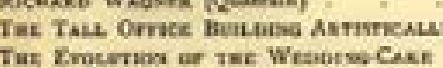

Anenst wisoms

A Lrru kear os Lon

PRICE TWENTY-FIVE CENTS

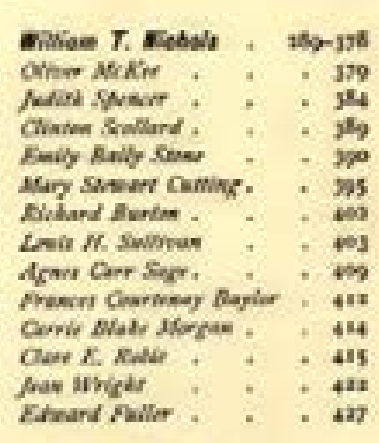

J:B:LIPPINCOTT:CO: PHILADELPHIA: LONDON: 10 HENRIETTA STREET, COVENT GARDEN.

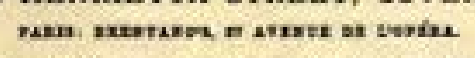

la representación, la imagen plástica y en ciertos casos, la represo público, migraba a la arquitectura en los albores de la modernidad. La historia de la arquitectura funcional-Zweckbau, definido su desencanto. En un lapso de veinte años, quedó claro que la arquitectura y la ciudad requerín una densidad de figuración mayor que la del correcto funcionamiento. En 1943, el historiador suizo Sigfried Giedion (1943), el plástico Ferdinand Leger y el urbanista Josep Luis Sert publicaron en los Estados Unidos, los "Nueve puntos sobre la Nueva Monumentalidad". Para Giedion no se trataba de renegar de las arquitecturas de las vanguardias a favor de algún tipo de revival o de historicismo, lo que a su modo llevaba a cabo el Realismo Soviético (Banham, 1965: Frampton, 1981). La "Nueva Monumentalidad" era un tipo de clarificación de la reciprocidad figurativa entre la ciudad moderna y las aspiraciones de la ciudadanía. La monumentalidad moderna fue definida por Giedion como una práctica continua entre arquitectura, escultura y pintura, paisajismo y urbanística, en un sitio despejado especialmente dentro del territorio de las ciudades, en el que se podría apreciar la imagen de tal univocidad entre los artefactos y las gentes que los encargan. El cristal de la "función" parecía haber enseñado a los arquitectos a construir las casas, las escuelas y las fábricas del mundo moderno; se trataba ahora de aprender a formalizar los vínculos entre ese mundo moderno y las emociones de la comunidad. Una continuidad espacial y temporal entre valores, territorio y objetos (que a poco Le Corbusier [1946] \|lamó "espacio indecible o inefable") que, como un credo, iba a percibirse por inmersión en él y por arrobamiento total de los sentidos. La monumentalidad moderna, una representación material en el espacio de imágenes no solo visuales o pictóricas, de los principios constitutivos de una comunidad, era una cualidad a que la arquitectura del siglo XX se acercaba en segunda vuelta. La corrección del espacio paso de depender del "casi nada" más que la función, a requerir "casi todo" más que solamente ella 
(Frampton, 1981). La ética se desplazaba de la inexorabilidad de la eficacia, a la epifanía de la significación. De una u otra manera, desde la Posguerra no solamente la función sino la arquitectura funcional, la arquitectura de los CIAM es puesta en crisis de modo manifiesto. De hecho, si la arquitectura era monumental, no podía ser moderna mucho menos, si era moderna, debía ser monumental.

La fundación de los Congresos Internacionales de Arquitectura Moderna en 1928, había respondido a la necesidad de superar cierta discontinuidad o indiferencia entre la moderna arquitectura de las vanguardias de Entreguerras y la agenda pública La estética de arquitectura de las vanguardias y del urbanismo funciona requerían de los individuos una suspensión gráfica de sus costumbres, gustos y recuerdos por gracia de un tipo de ascensión moral implícito. Lo cual, hacia la mitad de siglo XX, no había sido logrado. La crítica operativa a este desfasaje provino sobre todo de los jóvenes arquitectos ingleses a partir de 1947, mediante una posición que al tiempo que pretendía reconstruir un puente entre los individuos y el ambiente de las nuevas ciudades, cumpliera acaso por primera vez, el apotegma innegociable de la arquitectura moderna: que las cosas, que sus materiales, que sus dispositivos se vean como son, como lo que son. Las reformulaciones se produjeron a varios niveles: defección de los esquemas modernistas de CIAM, lógicas menos lineales y causalistas para el diseño de las ciudades y una honestidad sin transigencias, en que la imagen de los edificios y las ciudades no cedía ante el dictado de una ficción perfeccionista y objetiva, que poco tuvo que ver con la realidad y la capacidad productiva de la arquitectura contemporánea, y que literal y fenoménicamente era tan superficial como otro estilo.

Tanto G.C. Argan (1965) como R. De Fusco (1967) trataron de trazar el derrotero final del proyecto de la modernidad ante la evidencia de la mecanización definitiva de los procesos creativos. Los signos que los hombres dejaron en el proceso de su adaptación al ambientey la producción de objetos de uso en el pasado (que traspasó los límites funcionales de la cosa), participan de un impulso que rescata cierto deseo es un producto que no se consume y encarna aún, algo de utopía. Ante la perfectibilidad inexorable de los procesos de diseño industrial el arte de los monumentos demuestra "a Dios, que los hombres son todavía capases de "alguna cosa". (Figura 4) Así, los templos que construyeron Le Corbusier y Cottfried Böhm en la Posguerra, en Francia Alemania promedian la distancia entre el barroco delante del cual se siente exaltado el individuo- y los objetos industriales -ante los que ha de resignarse hombre a no repetir tal tipo de perfección. Este barroco de materiales modernos, ensamblados con perfección pero sin ánimo de disimular los encajes de las piezas de acero - de las tablas cepilladas de los encofrados del hormigón armado, a poco constituyeron las marcas visibles de lo que Banham describió como Nuevo Brutalismo. Para De Fusco, la arquitectura tiene como finalidad primordial un mensaje de la mayor claridad y orden, de los que depende su eficacia. Se trata de exacerbar el valor comunicativo -o informativo- que no radica en una forma previsible $o$ en un proceso unívoco de formación, sino en la extrañeza y lo novedoso; en lo inédito y la entropía. (Figura 5)

Si la forma no derivaba del concepto de función, la vocación de la imagen tenía que provenir del entretejido de la existencia de los ciudadanos en la metrópolis. La pregunta por la finalidad es por aquello que los edificios que los ciudadanos consagran, estan llamados a ser.
Figura 4. Biblioteca Nacional Mariano
Moreno en construcción. En primer plat "Canto a la Argentina" (1967) en el centenario del poeta Ruben Dario, ob
Fioravanti, hoy reubicada

Figura 5. Los encofrados del hormigón
armado de la biblioteca. En el acápite de la fotografia, "las tartes de le lestructura se denominar par
un servivo
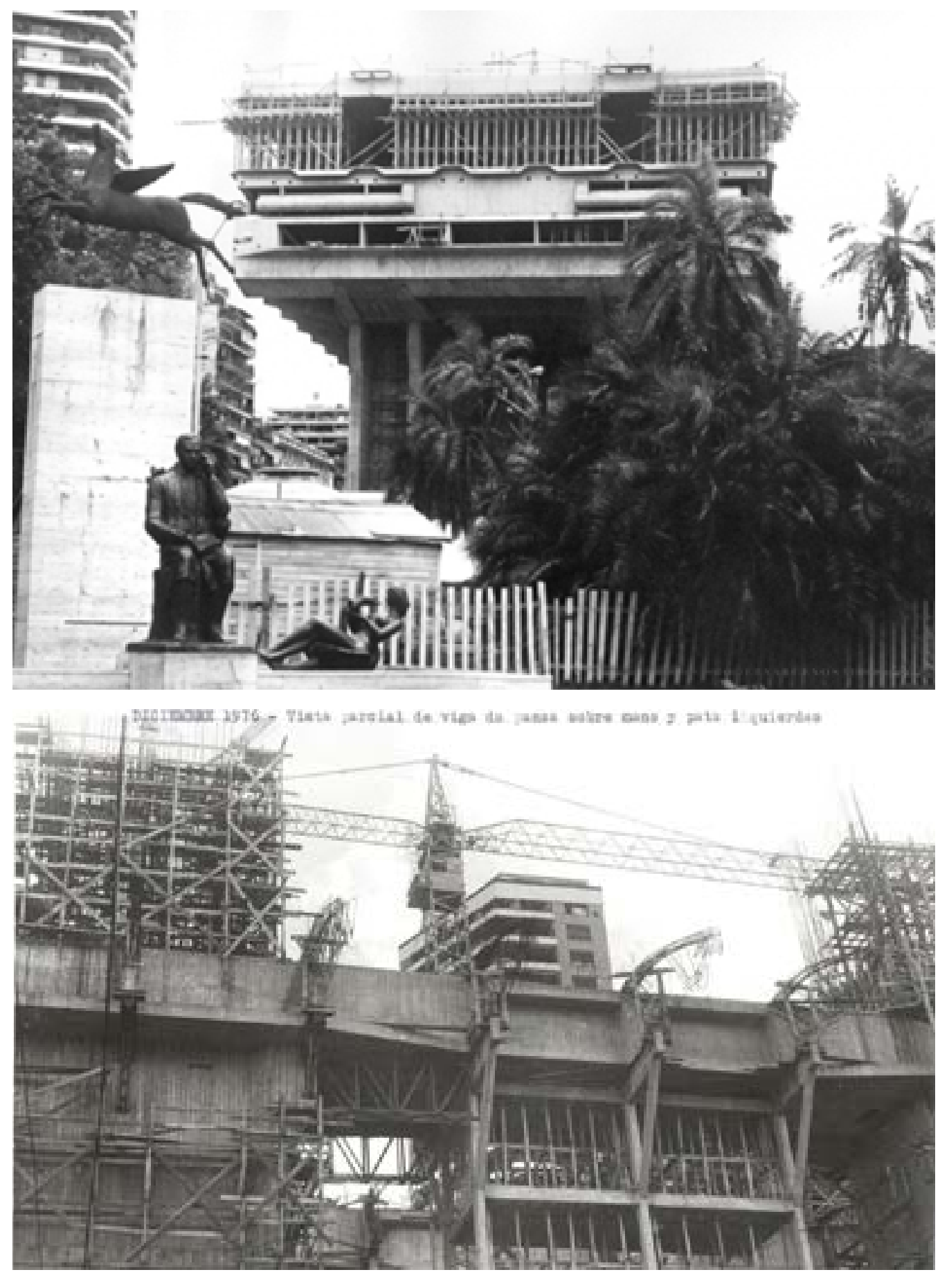

Anes de Investigacín enA 


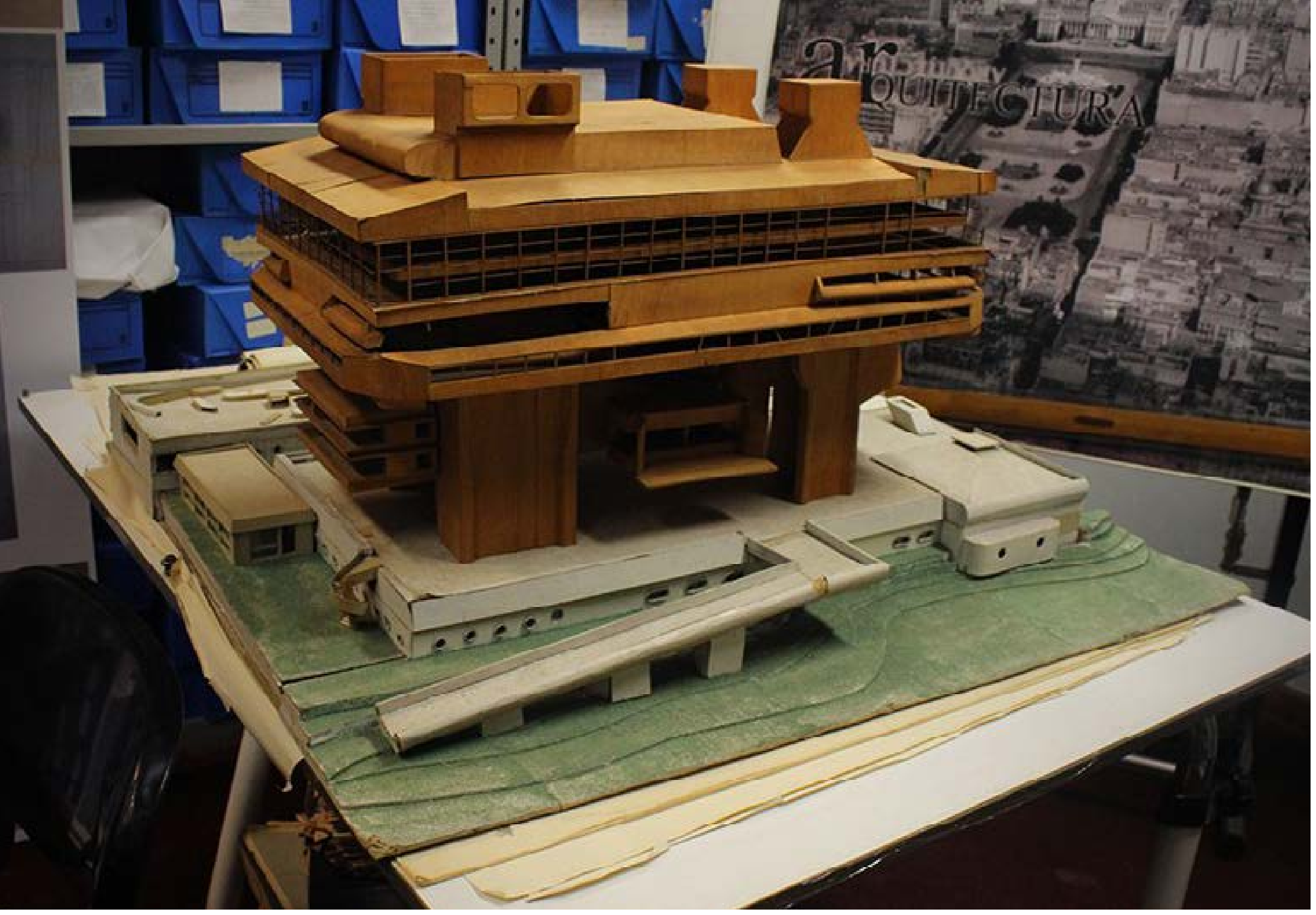

En arquitectura, marcada por expectativas de utilidad o eficacia, finalidad podría ser aquello que el edificio está hanado ser, comorepresentacion de las aspiraciones que

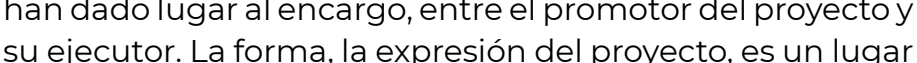
de factibilidad de ese encuentro, que suele manifestar matices diferenciados de realización La formulación matices diferenciados de reácación. La formulación 政 Encyclopédie méthodique (1788) . De hecho, el uso figurado de "Finalidad" méthod en la lengua francesa sino hasta 1819, asociada a la Causa o Fin (en Derecho, Filosofía y Biología). La arquitectura de las ciudades interpela al afecto o al
rechazo de los ciudadanos. La percepción sublime de estos
artefactos favorece la rápida comprensión e incorporación artefactos favorece la rápida comprensión e incorporación de las emociones que constituyen los valores básicos, sobre los que se instrumenta la vida colectiva de una comunidad. Los espacios institucionales urbanos en fecha de formación
de repúblicas modernas a mitad del SXIX y comienzos del
$X X$, presupusieron cierto consenso sobre la forma de los XX, presupusieron cierto consenso sobre la forma de los monumentos y espacios significativos, mientras que en tiempos recientes las formas adoptadas o elegidas parecen derivar más frecuentemente de una polémica. Ciertos espacios manifiestan y sostienen una relación mediata, ambigua, abierta, inacabada, que interpela al individuo que los percibe y con los que las instituciones intentaron 2014) (Figura 6)

Esta dimensión no revelada en el propósito de un edificio, es su finalidad: aquello que de algun modo este está Ilamado a ser y es develado en el trabajo del proyectista. El propósito no implicito en el edificio, que la finalidad a que se ha encomendado revela, impone ciertas configuraciones materiales que seguramente permaneceran al margen de la duración del destino primero. La idea del monumento que permanece, refiere a la "arquitectura de la ciudad" 
(Rossi, 1966). La construcción de un edificio participa principalmente de la lógica de construcción de la ciudad Aquella dimensión no revelada en sus condiciones de construcción pero que el proyectista ha develodo, puede perdurar. Tal "finalidad" es no tanto un "venir a propósito de" sino un "crear un propósito en". Un edificio satisface - las circunstancias del encargo y al mismo tiempo da a las circunstancias del encargo y al mismo tiempo da puente de la figura del Heideger (1951), un proyecto no solo refiere a la oportunidad para la que debe ser propio solo refiere a la oportunidad para la que debe ser propio, determinada manera, de donde deviene su pertinencia.

El "Nuevo brutalismo" se presentó a sí mismo como crítica a las propuestas de CIAM, del cuarto de siglo anterior Abreva en las experiencias de la arquitectura de las vanguardias de entreguerras tanto como en la arquitectura del Humanismo y el Manierismo. Recoge las experiencias de la urbanística de Le Corbusier y Gropius, pero corrigiendo en ellos la potencialidad para construir espacios de coexistencia comunitaria, de convivencia y morada. Peter Smithson refería en él un "doricismo topológico": las maneras de conducirse dentro del ámbito democrático de las Acrópolis, a diferentes puntos entre sí. Interesa del Nuevo Brutalismo, las formas que ha dispuesto en el diseño de las ciudades: la calle o la galería, los puntos de encuentro, los ámbitos en los que la comunidad se constituye. A modo de clusters y cúmulos, la geometría de la urbanística nuevo-brutalista es imperfecta, inacabada, siempre in progress. El Nuevo Brutalismo resultó muy atractivo de adoptar por los arquitectos de todas latitudes. A su modo novedoso y distinto; imperfecto y abierto; más sistémico y organico que funcional, lucia en su superficie por principio, las marcas del trabajo, las huellas de una comunidad. Debe reconocerse que los principios aplicables del materia as found, la exhibición de complejas soldaduras entre elementos de acero y todo tipo de correcta juntura entre materiales, se redujo finalmente a la exhibición en bruto de todo tipo de acabados de tecnologías menos sofisticadas, por lo que resultó tan pertinente para economías e industrias no desarrolladas. Al cabo de las vanguardias, reintroducía una forma de auténtica historicidad en la construcción de la ciudad. Contrastantes pero definidos, no-modernos sino monumentales, los edificios nuevobrutalistas despejaban en las ciudades el espacio para su percepción. Esta visibilidad "barroca", interpeló el jucio estético de los ciudadanosy los movilizó a valpeló el juicio artísticos-arquitectónicos aparecidos en tal paisaje urban que tomaba razón de ser en torno de ellos.

\section{Barroco y brutal}

"Como complemento del llamado a las fuerzas populares y al culto de las masas para la lucha contra la Reforma, el Catolicismo había dado vida a un renacimiento vigoroso del artesanado pidiéndole convertirse en el patrón de todos los recursos de la técnica y fundir en una sola espectacular fenomenización de lo real a la experiencia de la naturaleza, de la vida social y hasta de la política, con el fin de mostrar cómo las posibilidades de la imaginación siguen naturalmente a la creación por una vía señalada por la Providencia, mientras que la fantasía o la utopía llena al mundo de quimeras y fantasmas.

Argan, G.C. "Progetto e destino", 1965

El proyecto para la Biblioteca Nacional Mariano Moreno era historia incluso antes de ser construido. (Figura 7) En la "Arquitectura Argentina Contemporánea. Panorama de la arquitectura argentina 1950-1963", Francisco Bullrich (1963) coautor del proyecto de la Biblioteca, dos páginas ilustran el corte, la maquetay la implantación en los jardínes de Agüero y Libertador (Bullrich, 1969). Para Bullrich, la filiación de un Brutalismo local, a mitad de camino entre el impacto del golpe de timón corbusierano de

\section{ARQUITECTURA ARGENTINA CONTEMPORANEA}

Francisco Bullrich
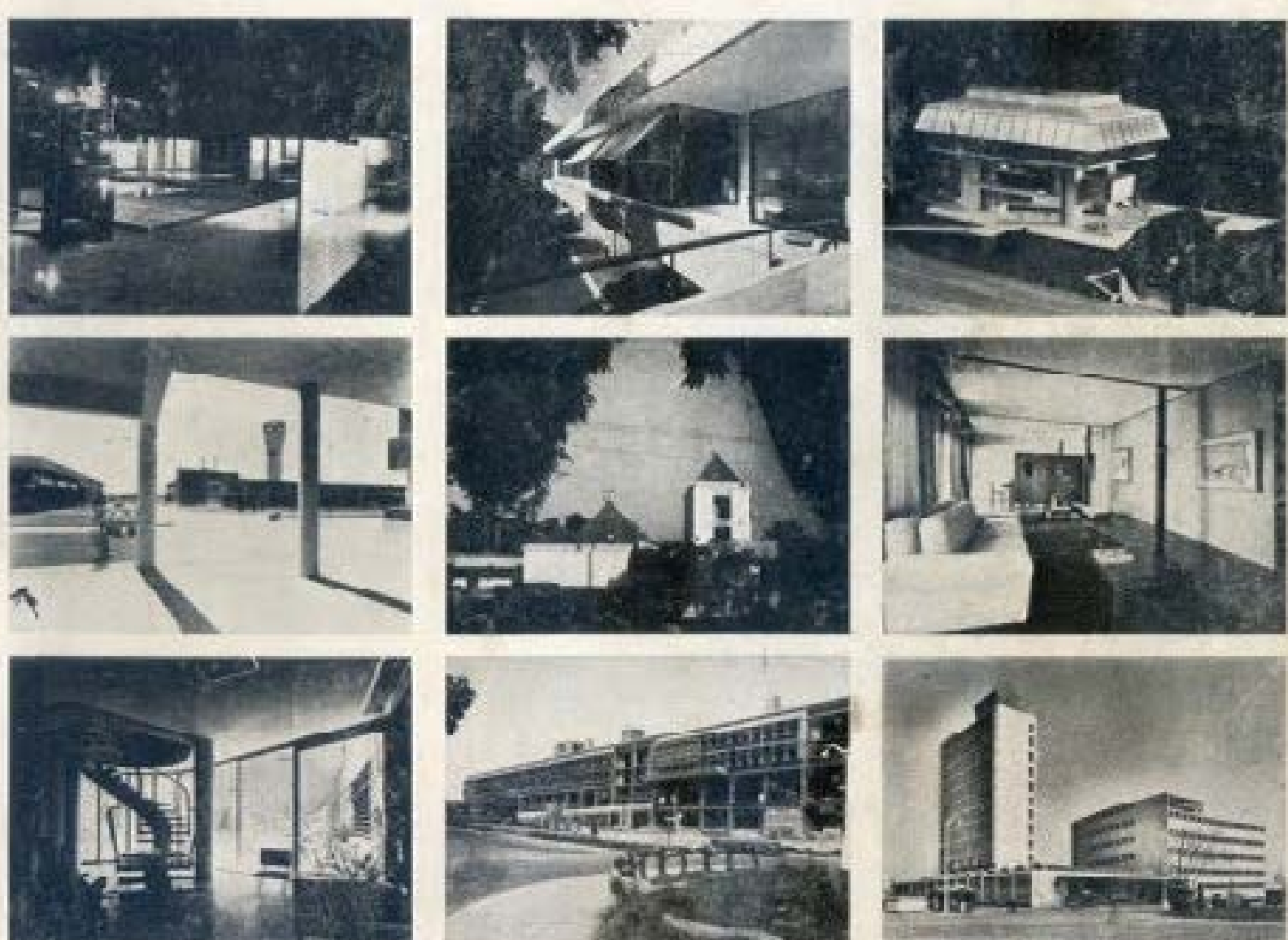

10
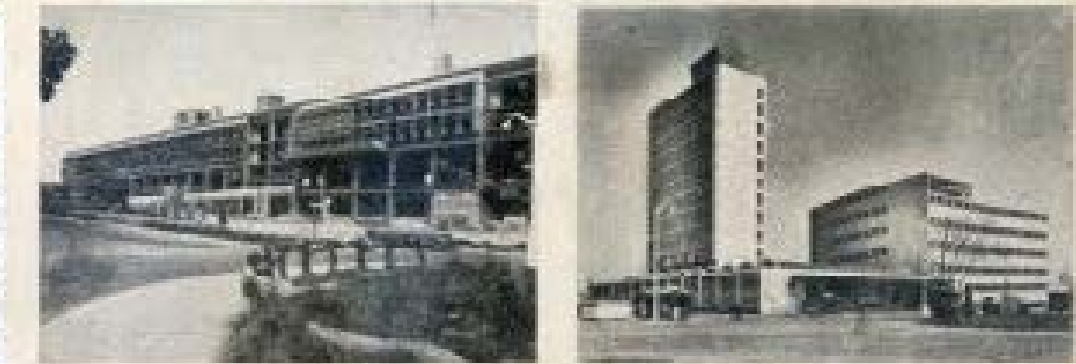

Ediciones Nueva Visión Buenos Aires

Figura 7. Fotografia de la misma maqueta en la portada de Bullich, F. (1963): "Arquitectura argentina contemporánea". Buenos Aires, Nueva Visión. 
Posguerra y un vernaculismo inspirado en la "arquitectura sin arquitectos" del noroeste argentino, resultaba una salida por ambos caminos, el de la realidad tecnológica (el hormigón armado de encofrados artesanales) y de la Biblioteca, como la sede el Banco de Londres en Buenos Aires, dos proyectos en los que intervino el maestro Testa sin embargo, exhiben un diseño menos trascendto Testa el brutalismo del vernáculo (Plotquin, 2018) y con maye audacia. El empleo del hormigón armado resumayor estos proyectos, el pasado y el futuro, presentando ciert estos proyectos, el pasado y el futuro, presentando cierta de encofrados metálicos de gran compromiso técnico. material estructural es al mismo tiempo la plástica y en material estructural es al mismo tiempo la plastica y en es decir, mucho más que el repertorio de pies derechos y es decir, mucho más que el repertorio de pies derechos de la primera mitad del siglo XX. Tal respuesta satisface la triple ecuación de una obra moderna, acentuadamente triple ecuación de una obra moderna, acentuadamente la práctica (y de la teoría) del proyecto en Buenos Aires. La opción enfática por el carácter de un edificio autónomo de todo clisé estético superfluo, configura en sí misma un objeto monumental fuera de serie, derivado de su finalidad: de aquello que representa y está llamado a ser. En 1962, se trataba de cargar de contenidos simbólicos con la mayo contundencia material, a la pretendida transparencia modernista entre el aspecto de la cosa y la cosa en si. Es evidente que, toda vez que la retórica no fuera por el funcionamiento, la representación de la mera eficiencia y la sola funcionalidad pasaban a un segundo plano. E edificio para la Biblioteca en su escenificación técnica, es una forma evocativa de la resistencia del discurso de la cosa pública cuando le es imperioso volver a tomar forma (ese rasgo apolíneo que la modernidad suprimió de la figuración plástica); de la resistencia del proyecto moderno más alla de la categoría ilusoria de la modernidad y de la cristalización, con la eficacia sólida del monumento, no de lo que ha venido sino de lo que está por venir.
Jorge Francisco Liernur (1982) analizó este caso en los seminarios de historia de los talleres informales para estudiantes y arquitectos conocidos como "La Escuelita", que funcionaron en Buenos Aires hasta 1983. Transcurrían dos décadas desde el llamado a concurso y el edificio de la Biblioteca permanecía inconcluso y abandonado. Faltaban diez años más para que fuera inaugurado en 1992. Inacabado, el edificio representó forzosamente otra cosa: la molicie burocrática, los vaivenes financieros de las agendas públicas, y al fin, el papel que el acervo literario jugaba en ese trascurso. Es un hecho que cuando el ciclo desarrollista que había iniciado Arturo Frondizi pasó a la historia, los trabajos en la Biblioteca se fueron paralizando paulatinamente. Así pues, cuando fue inaugurada, represento a su vez una cosa nueva: el resignado fina de su falta de conclusión. ¿Cómo verificar treinta años después, si lo que los autores esperaban del proyecto era esto que acababa de ser terminado? Comparado con los shoppings de oropel y vecinas torres de departamentos de casi $100 \mathrm{~m}$ de altura, el gusto por la contemplación de la Biblioteca, quedaba demorado. De los tres autores de proyecto, Clorindo Testa había aportado su genio en otros públicos de magnitud, muchos de ellos consumados en el ciclo de facto de 1976-1983, lo que determinó cierta sombra sobre el juicio estricto de estas obras (Liernur, 2004).

Liernur (1982) puso en relación a la especificidad disciplinar de los arquitectos, el lugar de la técnica y al genio, como valores para llevar a cabo una arquitectura contemporánea argentina. Esos rasgos permiten delinear el concepto de finalidad que aquí se persigue. La ocurrencia de estos tres argumentos correspondió a un punto de quiebre en la producción arquitectónica en Buenos Aires. Liernur encuentra vínculos manifiestos entre el proyectar la Biblioteca y el escribir la Historia en Bullich: a las aspiraciones públicas y políticas, se superponía a la Biblioteca un compromiso estrictamente disciplinar. El proyecto ganador provee por añadidura otra finalidad específica, señalando un futuro posible para la arquitectura inmersa en la industria de la construcción argentina. Para Bullrich, graduado en Buenos y formado en la Hochschule für Gestaltung -Ulm, la supresión moderna de valores como "forma" o "composición", no había venido acompañada de la producción de nuevos valores base de "la supervivencia de toda cultura". Sentadas nuevas condiciones históricas de producción, debíase entablar un tipo de vínculo entre las artes y la industria, aún no logrado, como el que oportunamente las artes establecieron con los sistemas productivos medievales o renacentistas (Shmidt, 2015). Cita a Max Bill: "Se ha hecho evidente que no puede tratarse solamente de desarrollar la belleza a partir de la función, debemos exigir antes que la belleza, yendo a la par de la función, sea ella misma una función" (Bullrich, 1957). Esa especificidad y ese futuro corresponden a la práctica excluyente del arquitecto y refleja Bullrich también su perspectiva a cierto conflicto contemporáneo sobre incumbencias profesionales, que parece evidente en el llamado al Concurso.

La recuperación de la forma como medio específico de Un artista-artesano, desplazado por la realidad productiva 
de la condición moderna. En la propuesta historiográfica de Bullrich, intuición y genio eran dos valencias que garantizaban la permanente adaptación a la siempre cambiante (sucesivamente modernizada) condición de la industria y la tecnología. El factor biotécnico (función) conjugado con la expresión, desarticulada esta de toda conjugado con la expresion, desarticulada esta de toda facilitada por el genio. En todo caso, Liernur ha planteado facilitada por elgenio. En a favor de una to ha lanteado que en el vinculo autoral de Bullicich y Testa tiene lugar e balance entre los dos modos de entender este proceso de sintesis. el arte concreto (apolíneo) y el informalismo (dionisiaco), respectivamente. La Biblioteca se plasma en que la arquitectura reveló su rol figurativo y simbólico en la fecha en que la agenda política desarrollista más lo requiere. Mientras que el florecimiento de la cultura pública (teatros, exposiciones, conciertos, cine) parecen ser pública (teatros, exposiciones, conciertos, cine) parecen ser agenda pública desarrollista parece enfrentar un dilema ¿cultura o desarrollo? Para sus dirigentes, las técnicas y la tecnología debían quedar incluidos dentro de la reforma o revolución cultural...Es notable el rol divulgador que o revolución cultural...Es notable el rol divulgador que panorama argentino desarrollaron en ese período por caso, la acción cultura de Olivetti de Argentina.

El proyecto de la Biblioteca Nacional configuró un tramo de la agenda nacional plagado de idas y vueltas, lo que no desmerece el lugar que la Cultura tenía en el proyecto modernizador/industrializador de Frondizi. La omisión de la particularidad técnica en la fase política del debate por la Biblioteca, oculta de hecho una debilidad en el estado rea de imaginación en ese campo, disimulado por la urgencia de una intensa figuración del sentir y de la idiosincrasia de la época (Liernur, 1982). Si el proyecto de la Biblioteca se inserta dentro de las metas de un gobierno, cuyo objetivo primordial fue el desarrollo, para desmentir o compensar tal inclinación, el concurso para la Biblioteca se present ambiguo respecto de lo técnico, pero firme respecto de la relevancia de la Cultura. Dirigentes y promotores refieren ella como "Partenón", "baluarte" y "templo" del saber". Los medios tecnológicos del presente hacen pasar por fósiles a los requisitos que plasman las bases del Concurso, en que se define la construcción de la Biblioteca en un lugar "despejado" del tejido de la ciudad (acaso en los té rminar "de Ciedion): el predio de la malograda residencia Unzus último domicilio de Perón y su mujer, vandalizado tras su caíla. En este enclave, la Biblioteca se presentarí como follie y objetc trouvé en el parque. (Figura 8)

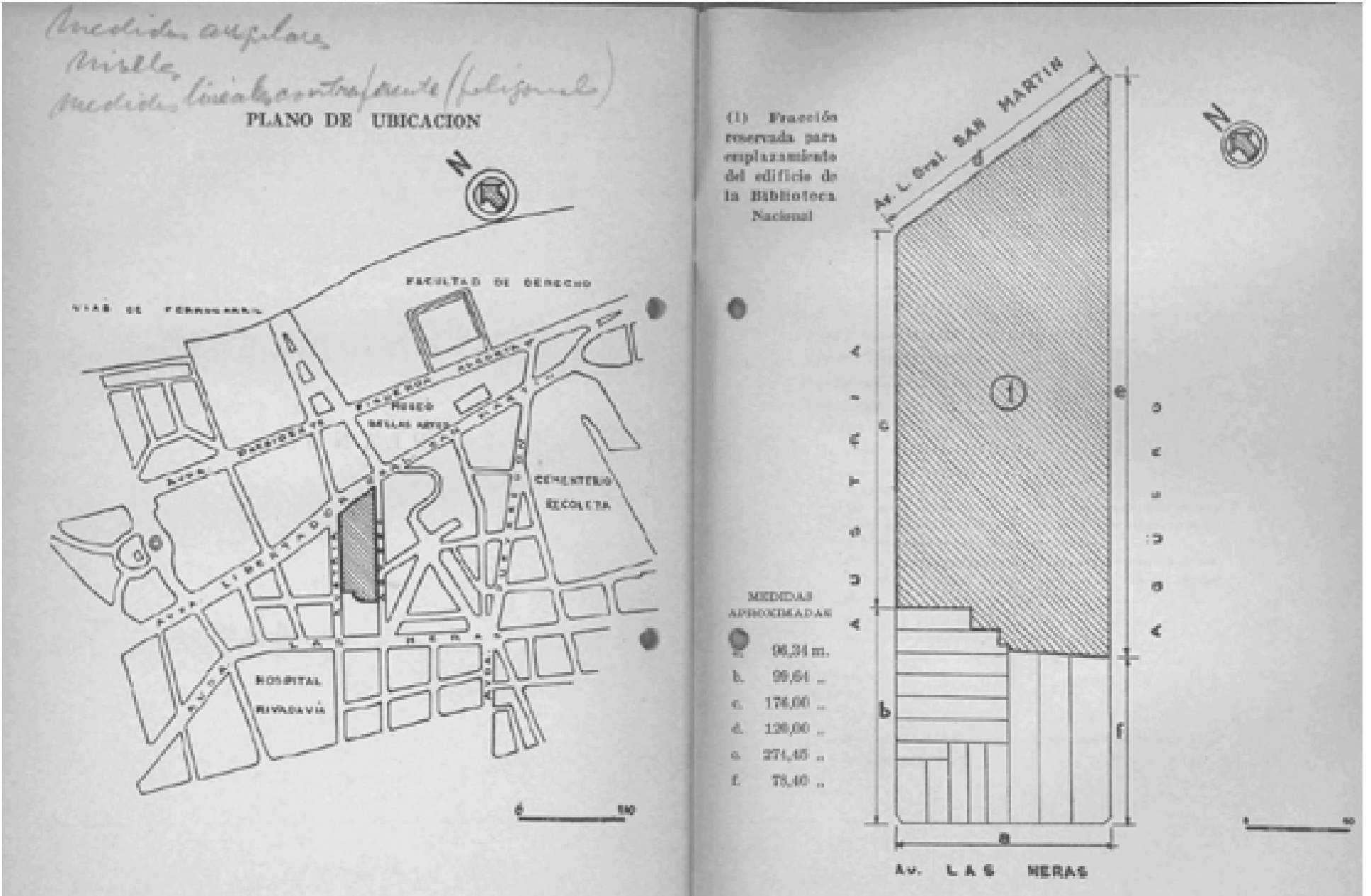

Figura 8. El predio para la nueva sede de la Biblioteca, tal como se presentaba en las bases del concurso 


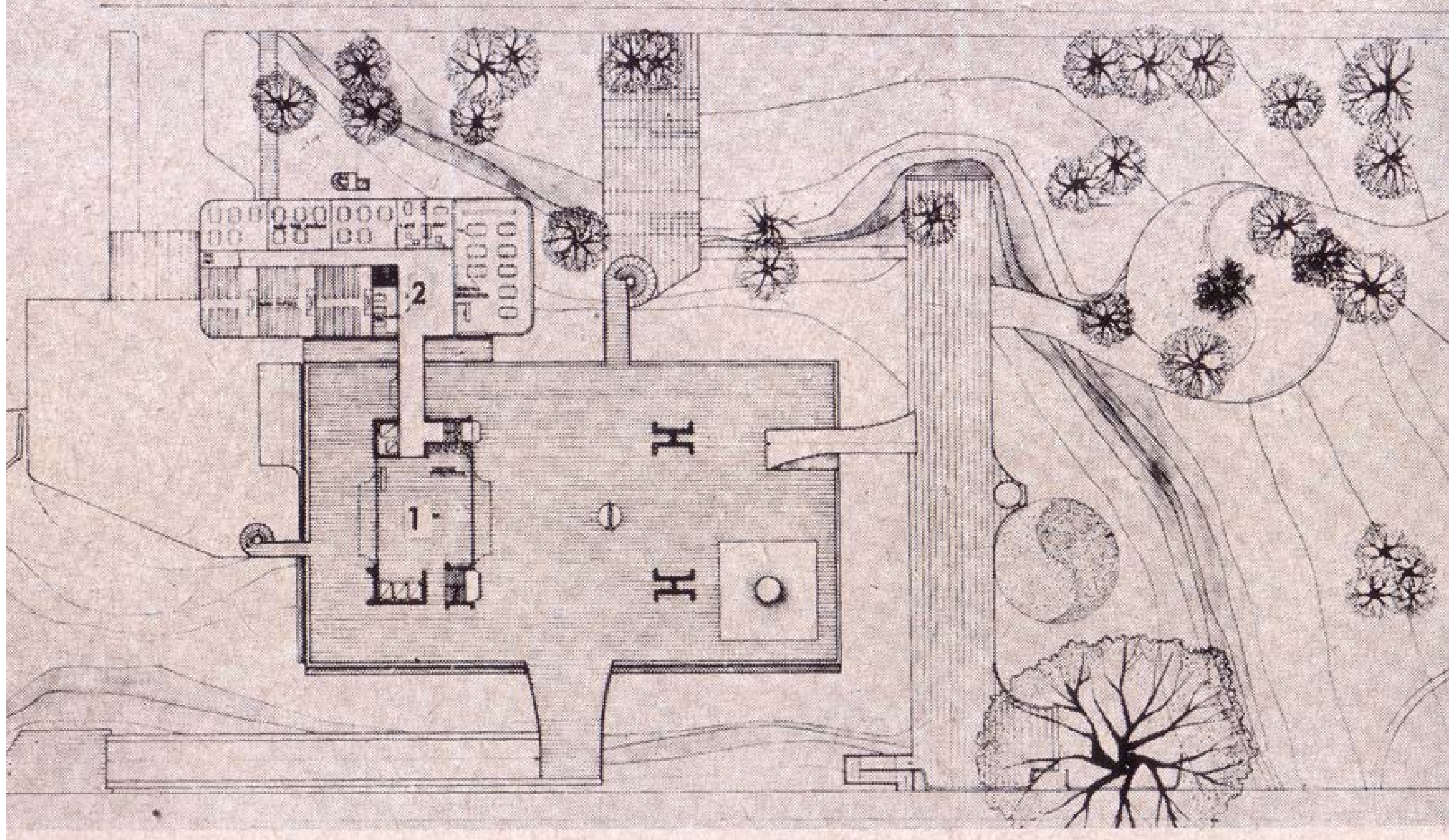
serie completamente diferente se apoya sobre por presencia u omisión contribuyen a figurar la finalidad esperada por el Jurado para la futura sede de la Biblioteca. (FIGURA_10) La monumental "tienda" de piel de 
aluminio de la estirpe de los proyectos de Etienne Louis Boullee, destaca por el "vuelo lírico" que corresponde a la importancia del tema y del lugar. La lírica y la sublimidad del caso no parecen señaladas en el fallo del primer premio como si a cada tipo de proyecto, el Jurado reconociera su arista particular. De ahí la relevancia de todo lo que ha sido dejado de lado en la adjudicación del ganador. La forma exótica en la propuesta del equipo de Solsona dirige "la sensibilidad hacia nuevos caminos formales y estructurales", compite con el valor simbólico y paisajístico asignado al predio. Es una total innovación. El golpe de asio supera la necesidad de adaptación a la realidad técnica de la industria argentina, y propone para ella gran salto del Desarrollo. Mientras que el primer premio destacó por la suerte de expresión adecuada a la realidad técnica local, el segundo pretende una modernización técnica ideal. La propuesta de Solsona era "desprejuiciada creativa", como las nuevas generaciones urbanas en explosión cultural de los sesentas. El 12 de octubre de 1962 se inauguró la exposición pública de los proyectos en antigua Biblioteca de la calle México. Las palabras dirigidas allí por el arquitecto Adolfo Storni, asesor del Concurso, dan cuenta de cómo la arquitectura del monumento premiado había logrado constituir su finalidad ex post de las propias bases del Concurso y una vez premiada la propuesta. La cosa pública entre el suelo y el aire, por entre la que el espíritu libre buscará el camino (pero no en el suelo) y llegará a la verdad (al aire emancipador de la sala en la altura). Liernur ha sido enfático respecto del modo en que el gran monumento nacional estaba llamado a ignorar o idealizar a la ciudad en la que se implantaba, y en la que las jurisdicciones se entremezclaban de modo característico.

Mientras que la durabilidad ha sido una de las claves cruciales de los fallos del jurado, pues ella ha de esperarse para cualquier monumento público, para Storni "las obras del espíritu son las únicas que trascienden" notando la múltiple finalidad de la expresión "obra": arte, fábrica, construcción, misión.

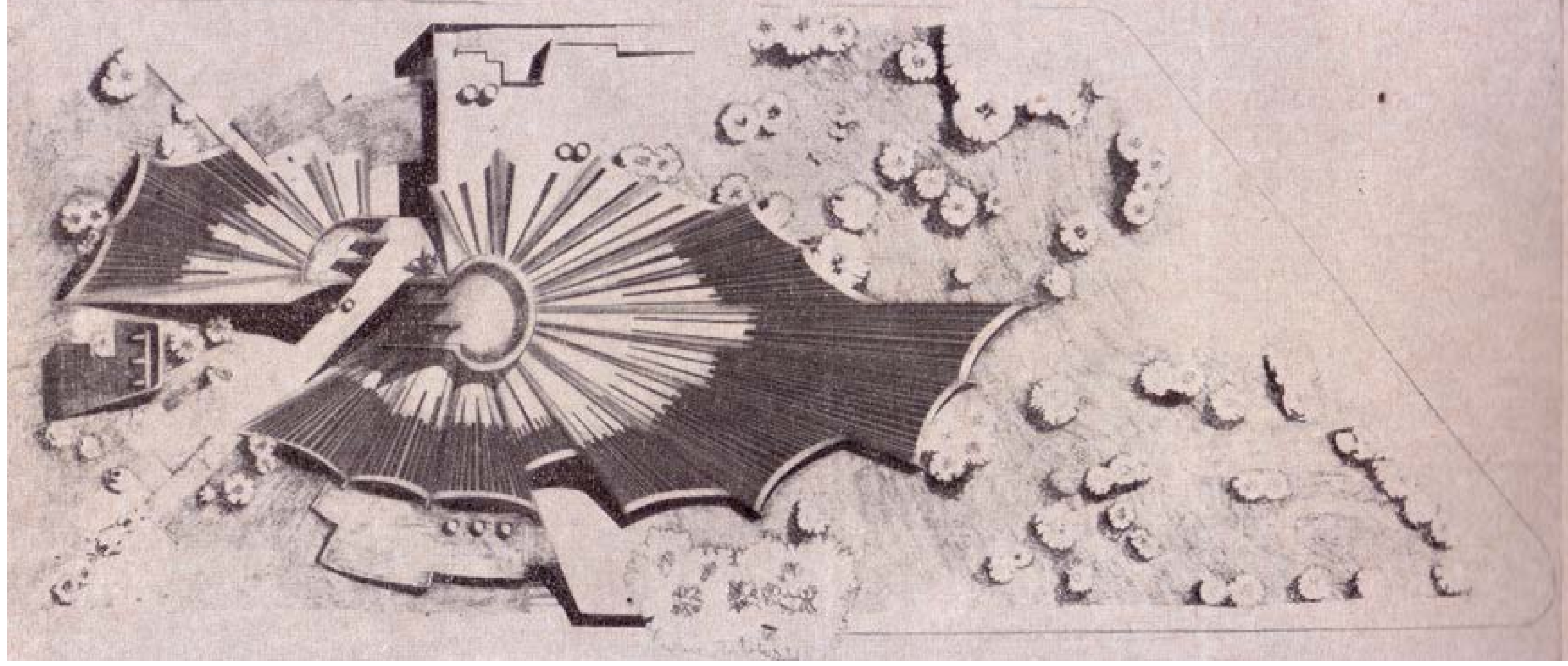

Figura 10. La Biblioteca en el jardin: planta del segundo premio del concurso, Manteola, Sánchez Gómez, Solsona y asociados

* Contribución: el trabajo fue íntegramente realizado por el autor.

El Editor en Jefe de la revista Arq. Carla Nóbile aprobó la publicación final del artículo. 


\section{Argan, G.C. (1965). Proyecto y destino, Milán}

Banham, R. (1955).“The new brutalism” en Architectural Record. December.

Banham R (1966). Brutalismo Barcelona Custavo Cill.

Behne, A. (1923-25) Die Moderne Zweckbau, Birkhäuser: Basel.

Boletín SCA no48 enero 1963

Bonta, J.P. (1977). Sistemas de significación arquitectónica. Barcelona, Gustavo Gili.

Bullrich, F. (1957) Algunos problemas del diseño. Nueva Visión, (9).

Collins, P. (1977). Los ideales de la arquitectura moderna. 1750-1950. Barcelona, Gustavo Gil.

DeFusco, R.(1970). Arquitecturacomo “mass-médium”. Notasparaunasemiologíaarquitectónica. Buenos Aires, Anagrama.

De Zurko, E.R. (1958). La teoría del funcionalismo en la arquitectura. Buenos Aires, Nueva Visión. Frampton, K. (1983). Historia Crítica de la Arquitectura Moderna. Barcelona, Gustavo Gill

Groys, B. (2014). Volverse público: las transformaciones del arte en el ágora contemporánea Buenos Aires, Caja Negra.

Heidegger, M. (1951). “Bauen, denken, wohnen"

Liernur, J.F. (1982). “Alpargatas, no. Libros, sí". Materiales. Buenos Aires, La Escuelita

(2004) "Testa, Clorindo" en Aliata, F.y Liernur, J.F. [Comp.] Diccionario de arquitectura en Argentina. Buenos Aires, AGEA

Plotquin, S. (2018). Grandes luces: Vivienda y arquitectura en el ciclo de producción de la energía eléctrica. Registros, Revista de Investigación Histórica. (14)]. Arquitecturas de Estado: obras, infraestructura, empresas (1929-1973).

Rossi, A. (1966). L'architettura della città, Marsilio Editore, Padova, 1966
Shmidt C. (2015) "Erancisco Bullrich y la historia de la arquitectura. Anotaciones en tres momentos" Vitruvia Año $2 \mathrm{~N}^{02}$

Sullivan, L. (1896) "The tall office building artistically considered". Lippincott's Magazine, Vol. 339, p. 403-409.
Figura 1. Testa, C. Biblioteca Nacional. Croquis s/f. Fuente: Archivo Patrimonio Histórico del Edificio Biblioteca Nacional.

Figura 2. George Washington (1840), Horotio Greenough. Fuente: American Sculpture Photograph Study Collection (S0001154).

Figura 3 "The toll office building artistically considered" de Louis Sullivan, en la portada del Lippincott's Magazine de 1896

Figura 4. Biblioteca Nacional Mariano Moreno en construcción. En primer plano, el "Canto a la Argentina" (1967) en el centenario del poeta Rubén Darío, obra de José Fioravanti, hoy reubicada. Fuente: Archivo Patrimonio Histórico del Edificio Biblioteca Nacional.

Figura 5. Los encofrados del hormigón armado de la biblioteca. En el aćpite de la fotografí las partes de la lastructura se denominan "patas" y "barriga", como si de un ser vivo. Fuente: Archivo Patrimonio Histórico det Edificio Biblisteca Nacionat.

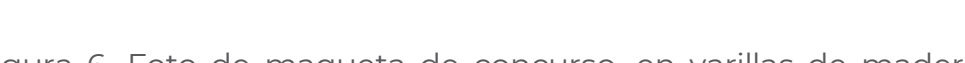

Figura 6. Foto de maqueta de concurso, en varillas de madera de pino. El aspecto escultórico supera al funcional e incluso tectónico. Fuente: Archivo Patrimonio Histórico del Edificio Biblioteca Nacional.

Figura 7. Fotografía de la misma maqueta en la portada de Bullrich, F. (1963): “Arquitectura argentina contemporánea”. Buenos Aires, Nueva Visión.

Figura 8. El predio para la nueva sede de la Biblioteca, tal como se presentaba en las bases del concurso. Fuente: Boletín SCA no48 enero 1963

Figura 9. La Biblioteca en el jardín: planta del primer premio del concurso, Bullrich, Cazzaniga y Testa. Fuente: Bullrich, F. (1963): "Arquitectura argentina contemporánea". Buenos Aires, Nueva Visión 